\title{
E-Service Application: Online Donation to Help Fight COVID-19
}

\author{
Iskander BelHaj Nasr ${ }^{1 *}$, Kabil Jbeli ${ }^{1}$, Abir Smiti $^{2}$ \\ ${ }^{1}$ Centre de Recherche et Innovation, Polytech Intl Group, Rue du Lac d'Annecy 1053, Tunis 1053, Tunisia \\ ${ }^{2}$ Larodec, Institut Supérieur de Gestion, Université de Tunis, Avenue de la Liberté Bardo, Tunis 2000, Tunisia
}

Corresponding Author Email: skander.ph@live.fr

https://doi.org/10.18280/isi.260114

Received: 20 November 2020

Accepted: 26 January 2021

\author{
Keywords: \\ donation, KNN, Artificial Intelligence, \\ COVID-19, E-service
}

\begin{abstract}
The Artificial Intelligence (AI) can promote research and find optimal solutions for complex and unstable situations. COVID-19 highlights the urgent need to innovate and offer modern solutions. Those solutions must meet the business requirement but also the current circumstances. In this paper, we are going to describe a new E-service application: Online Donation to Help Fight COVID-19. Our online donation software is perfect for nonprofits. The application has many features to suit our needs and their support response time. We use the Machine learning technique K-Nearest Neighbor to identify the ideal beneficiaries (school, hospital...). Our project can resolve the problem of donation management and establish the transparency and trust.
\end{abstract}

\section{INTRODUCTION}

The Coronavirus pandemic, which has spread into the world, has highlighted the infrastructure issues of the health and social systems in many countries. The health emergency was declared, and everyone (Health care staff, researchers, developers ...) has been mobilized to fight the virus and take the initiative to limit its exponential propagation. The World Health Organization (WHO) [1] has promoted innovation and invited stakeholders around the world to screen for the virus. International entities have also been mobilized to ensure global solidarity against a pandemic that was never expected.

In Tunisia, a controversy has been created in different platforms asking the Tunisian government and specifically the ministry of public health for more transparency especially concerning the status and expenses of the donation fund dedicated to the pandemic. During the crisis, the focus was mainly around the sustainability of the fight against COVID19 , at least in financial and budgetary terms, which are still ambiguous and do not sufficiently meet the requirements of this period.

Therefore, the fact of reproducing ordinary old methods has become impossible, in a context of complex and rapid transformation. It has become mandatory to mobilize and include other fields to contribute to the problem resolution. The development of a powerful tool that helps the state to manage donation and to share between beneficiaries has become a need. That tool is based on advanced re-search and techniques.

In fact, Artificial Intelligence is a set of techniques used to solve many complex problems. Those techniques will change practices in many areas such as management and economic models, the medical field, alliances between competitors, the optimal use of resources and the distribution of costs.

The need for the conception of a software that combines the machine learning techniques and functional donation management is now mandatory, especially that it inherits the best practices of management and the intelligence created with implementation of machine learning [2] algorithm.

In this paper, we are going to present a case study based on a new application of online donation to help fighting the COVID-19. Our project can resolve the problem of donation management and build the trust again between stakeholders due to the lack of transparency. We deploy a machine-learning technique named k-nearest neighbors. $\mathrm{KNN}$ [3] is mainly implemented to solve of both classification and regression. It classifies the data on how other similar data are classified. $\mathrm{KNN}$ is one of the most adequate method to predict [3] the ideal beneficiaries tô donate. In addition, the project offers other feature such as dashboard and stats, report generation that contains full description of the situation and the way how donators can donate exactly what the state expects.

The rest of the paper is organized as follows:

The second section is a state of art, which aims to describe similar projects and their limits against the field of our research.

The third section is a description of the goal of the new application.

The fourth and the fifth sections start to make the analysis on functional, non-functional needs and use cases related to the new application.

The sixth and the seventh sections establish the description of KNN deployment, our approach for the classification algorithm and the realization phase mockups carried out on this project.

\section{STATE OF ART}

Tunisia confirmed its coronavirus first case on 2 March 2020. Until February 2021 the number of positive new cases attends approximately 230000 cases.

Initially, a fund has been created where the Tunisian citizens and companies contribute to the fight against the coronavirus. In May 6, 2020, the amount reached approximately 198.3 [4]. million Dinars (MD). Until October 19, 2020 the Minister of 
Health confirm that 52 [5] million dinars has been spent from the fund. The problem that no details about beneficiaries and destination of the fund are clearly described.

The need, as it has been shorty described in the introduction, has never been implemented before (the application aims to manage medical gift dedicated to stop COVID-19 pandemic with the help of Artificial Intelligence). Few applications have been developed before to manage gifts and donations. For example, the "Gofundme" website [6], which aims, as mentioned on his official website, to collect money for anyone (friend, yourself...). However, on the same site, we can find some people who are not honest and who are not really in need for the donations.

The main difference between all the existing donation management applications and ours is that we use Artificial Intelligence in managing gifts and supplying them to the hospitals which are really in need for.

This application aims to ease the contact between the state and physical and moral third parties (funds).

\section{DESCRIPTION OF THE GOAL OF THE NEW APPLICATION}

The main goal of the project is to create a system that manage gifts and donations offered for the medical sector for COVID-19. Allows any third party in all over the world to contribute directly to resolve this problem by giving a donation that corresponds to the real needs of the public health ministry.

The project is a platform gives the current state and predict to the commission of donation in the Ministry of public Health, different possibilities of beneficiaries and choose in which beneficiaries or region that an outbreak can happen so that they would need more medical supplies for it.

The module of beneficiaries prediction is dynamic, independent and fully managed by KNN algorithm.

The implementation of KNN will be described in the next paragraph.

The Figure 1 Use case diagram clarify and summarize the details of the system's users (also known as actors) and their interactions.

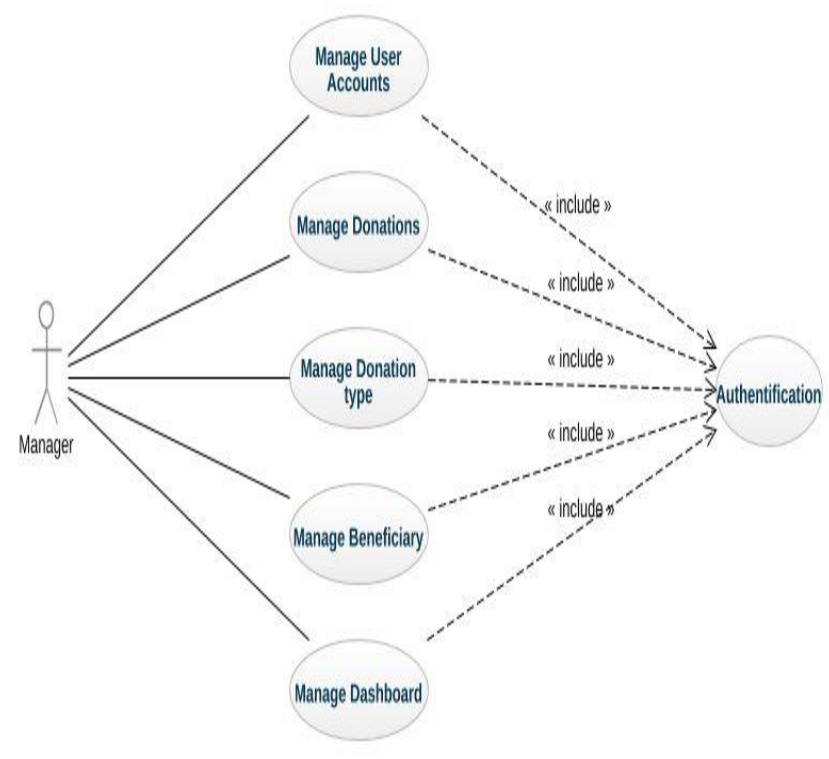

Figure 1. Use case diagram
This application must meet other needs to improve the quality of its functionalities, as this is a set of rules that must be observed when developing the application to ensure proper use:

(1) User-friendliness: The application should be simple and easy to handle by the user. User interfaces must be userfriendly, that is, simple, ergonomic and suitable for the user. The latter alerts the user whenever they accumulate a user error.

(2) Quality: The application must ensure the facilitation of access to data and the dissemination of information, reliability and traceability of data and the most intuitive human-machine interaction possible.

(3) Reliability: The quality of the content and the relevance of the information must be guaranteed.

(4) User management: The authorized administrator can view or delete all users and manage their right to access system functions.

(5) Availability: The application must be always available to the user.

(6) Security.

\section{KNN AND BENEFICIARIES}

THE SHARE

BETWEEN

\subsection{KNN algorithm}

The k-nearest neighbor method [7] $(\mathrm{KNN})$ is a supervised learning method. It is named nearest neighbors due to the behavior of this method:

Consider that $\mathrm{X}$ input and the objective of this method is to classify in the $\mathrm{k}$ inputs (training data) $\mathrm{Xi}$ among the examples learning which are "closest" to X, which is the input of the algorithm. Subsequently, the method will calculate the distance [8] for each of these entries to find the associated classes $\mathrm{Yi}$. To determine the class of a new object $\mathrm{X}$ :

(1) Choose the k objects from the training data that are close to $\mathrm{X}$.

(2) The distance calculation between $X$ and all objects in the training data.

(3) Assign $X$ to the class for which the number of the $\mathrm{k}$ nearest neighbors.

\subsection{KNN implementation}

The main purpose to deploy $\mathrm{KNN}$ in this project is to help the COVID-19 fund commission in the ministry to take a decision. The Euclidean distance method calculation is implemented in this project. Mainly this method produces who is the beneficiary, who needs the most.

For example, KNN will calculate the distance [9] between 2 objects (donations) as below:

$O_{1}=\left(X_{1}, X_{2}, X_{3}, \ldots, X_{n}\right)$ and $O_{2}=\left(Y_{1}, Y_{2}, Y_{3}, \ldots, Y_{n}\right)$ Where $O_{1}$ is a donation already shared and $O_{2}$ is a new donation.

The Euclidean distance [9] between two objects:

$$
D(O 1, O 2)=\sqrt{\sum_{i=1}^{n}\left(X_{i}-Y_{i}\right)^{2}}
$$

In this context, a beneficiary is any organization or third party which belongs to the state of Tunisia:

- Hospitals

- Low-income families

- Care centers 
- Others.

As described before that the application is based on configuration done by the administrator. Then, donators should only donate what the state needs. Also a beneficiary is characterized by information to describe their situation. Some of them are:

- Localization (Internal cities far from the capital or not)

- Needs and quantities

- Human capital

- Others.

Moreover, a donator can express his preferences. This means that during the donation some criteria could be filled like location, financial situation etc. to find the beneficiary. Those attributes will be decisive to make the decision, because they will shape the classes that KNN will classify.

$\mathrm{KNN}$ is a powerful classification [10] algorithm well known for pattern recognition [11]. That is why it is used in this project to classify new objects (donations) based on similarity measurement between donations already shared with beneficiaries and new donations not shared yet. Yet, before starting the process of classification, an important step is mentioned which is the normalization to get, at the end, a correct value of similarity [12].

\section{MOCK-UPS}

Realization is the last phase of building and setting up a project. This is one of the most important parts for the project to be carried out. In fact, we highlight mockups of the application interfaces.

\subsection{Sign in}

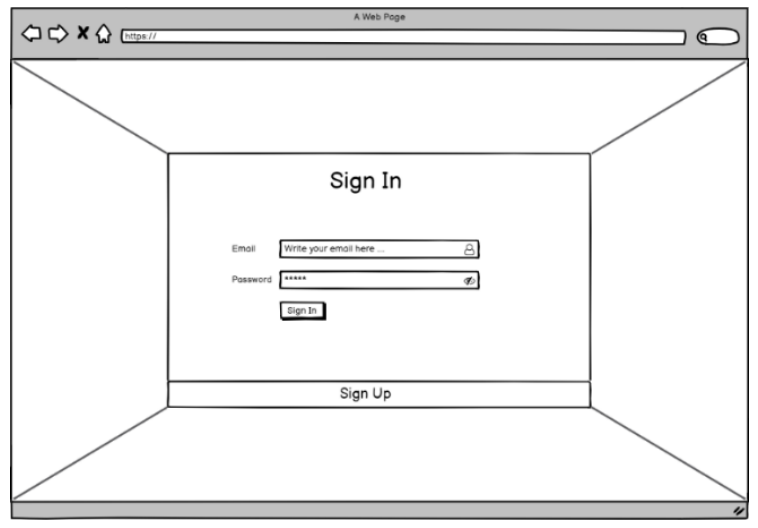

Figure 2. Sign in page

Table 1. Sign in page elements descriptions

\begin{tabular}{cc}
\hline Element & Description \\
\hline $\begin{array}{c}\text { Email } \\
\text { Password }\end{array}$ & $\begin{array}{c}\text { The user should write in thisinput his email address. } \\
\text { The user should write in thisinput his password. } \\
\text { When the user click on theSign In button he will } \\
\text { beredirected to his account screenif he write an } \\
\text { incorrectpassword an error message willappear on } \\
\text { the sign In form. }\end{array}$ \\
Sign In & $\begin{array}{r}\text { When the user click on theSign Up button he will } \\
\text { beredirected to the sign Up page }\end{array}$ \\
Sign Up &
\end{tabular}

Through this screen sign in visualized in Figure 2, the user can connect to his account through writing his email address and password that was submitted during the account creation.

The Table 1 describe all the different components and elements that exist in the sign in page represented in The Figure 2 by giving the main functionality of each element.

\subsection{Sign up}

Figure 3 visualizes the screen sign up where the user can create an account from which he can access the application.

The Table 2 describe the components that exist in the signup page represented in The Figure 3 through giving a short description for each element.

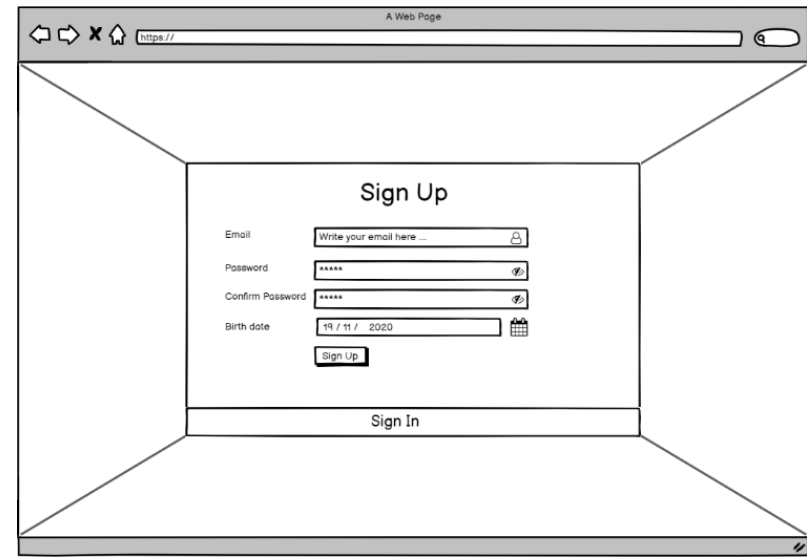

Figure 3. Sign up page mockup

Table 2. Sign up page elements descriptions

\begin{tabular}{cc}
\hline Element & Description \\
\hline Email & $\begin{array}{c}\text { The user should write through this input his } \\
\text { email address. }\end{array}$ \\
Password & $\begin{array}{r}\text { The user should write through this input his } \\
\text { password. }\end{array}$ \\
$\begin{array}{c}\text { Confirm } \\
\text { Password }\end{array}$ & $\begin{array}{c}\text { the user should confirmthrough this input the } \\
\text { passwordthat has been written in theprevious } \\
\text { input. }\end{array}$ \\
Birth date & $\begin{array}{c}\text { The user should provide through this input his } \\
\text { birthdate. }\end{array}$ \\
Sign Up & $\begin{array}{c}\text { When the user click on theSign Up button he } \\
\text { will beredirected to his accountscreen. }\end{array}$ \\
Sign In & $\begin{array}{c}\text { When the user click on theSign In button he will } \\
\text { beredirected to the sign In page. }\end{array}$ \\
\hline
\end{tabular}

\subsection{Home}

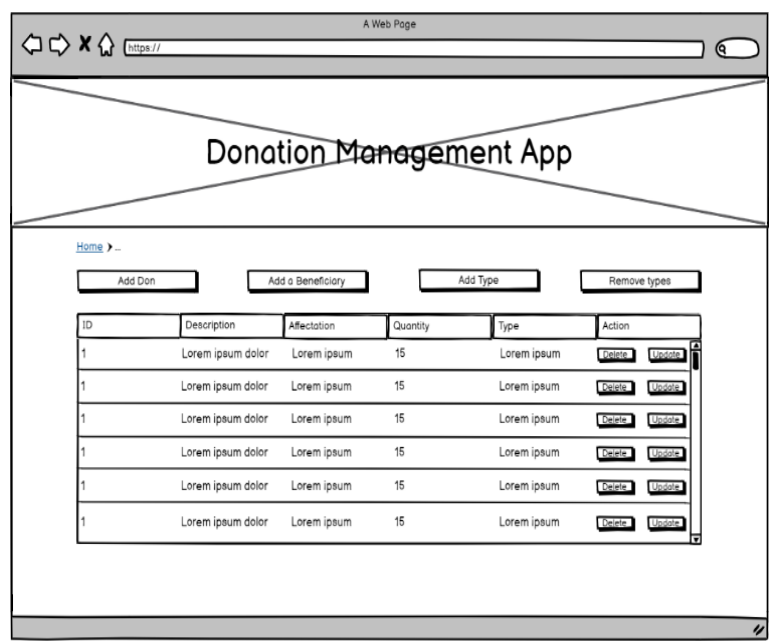


Figure 4. Home page mockup

Table 3. Home page elements descriptions

\begin{tabular}{|c|c|}
\hline Element & Description \\
\hline $\begin{array}{c}\text { Add } \\
\text { Donation }\end{array}$ & $\begin{array}{l}\text { When the user click on the AddDonation button a } \\
\text { pop up willappear on the screen to add anew } \\
\text { donation into the system. }\end{array}$ \\
\hline $\begin{array}{c}\text { Add a } \\
\text { Beneficiary }\end{array}$ & $\begin{array}{l}\text { When the user click on theAdd a Beneficiary } \\
\text { button a popup will appear on the screen toadd a } \\
\text { new beneficiary into the system }\end{array}$ \\
\hline Add type & $\begin{array}{l}\text { When the user click on theAdd type button a pop } \\
\text { up willappear on the screen to add anew type into } \\
\text { the system }\end{array}$ \\
\hline $\begin{array}{l}\text { Remove } \\
\text { types }\end{array}$ & $\begin{array}{l}\text { When the user click on theRemove types button, } \\
\text { a pop upwill appear on the screencontaining a list } \\
\text { of differentdonation types in which theuser can } \\
\text { select a type toremove it from the application } \\
\text { system. }\end{array}$ \\
\hline Data table & $\begin{array}{l}\text { Through the data table the usercan consult all the } \\
\text { differentinformation related to the latestdonations } \\
\text { that has beenpreviously added into the system. }\end{array}$ \\
\hline
\end{tabular}

The Figure 4 highlights the home page screen, the user can access the different features of the application (Adding a new Donation, adding a new beneficiary, adding a new donation type, removing a donation type...).

The Table 3 highlight all the components that exist in the home page represented in The Figure 4 by giving the main functionality of each field.

\subsection{Add donation}

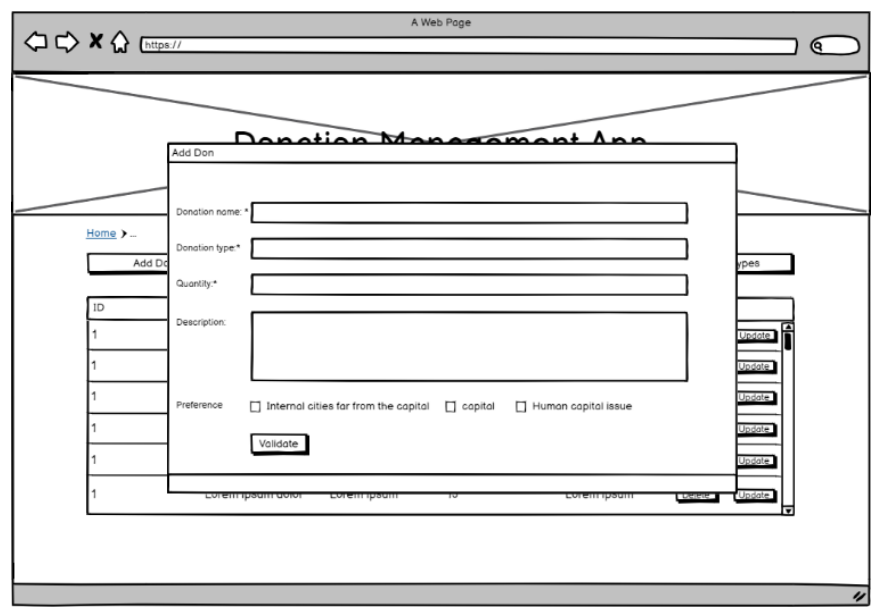

Figure 5. Add donation page mockup

Table 4. Add donation page elements descriptions

\begin{tabular}{cc}
\hline Element & Description \\
\hline $\begin{array}{c}\text { Donation } \\
\text { name }\end{array}$ & $\begin{array}{c}\text { The user should write in thisinput the name of } \\
\text { the donation }\end{array}$ \\
$\begin{array}{c}\text { Donation } \\
\text { type }\end{array}$ & $\begin{array}{c}\text { The user should choose the listin the dropdown } \\
\text { combo box adonation type to attach it to thenew } \\
\text { donation }\end{array}$ \\
Quantity & $\begin{array}{c}\text { The user should write in thedonation quantity in } \\
\text { this input. }\end{array}$ \\
$\begin{array}{c}\text { Description } \\
\text { Preference }\end{array}$ & $\begin{array}{c}\text { The user can provide a shortdescription for the } \\
\text { newdonation }\end{array}$ \\
regionrecipients of the new donation.
\end{tabular}

Through the add donation pop up the user can add a donation into the system through providing the donation name, donation type, donation quantity, description and the preference (Internal cities from the capital, capital, human capital issue). The Figure 5 displays details of the screen add donation.

The Table 4 specify all the different components and elements that exist in the Add donation page represented in The Figure 5 and how the user can interact with the different components in the page.

\subsection{Add a beneficiary}

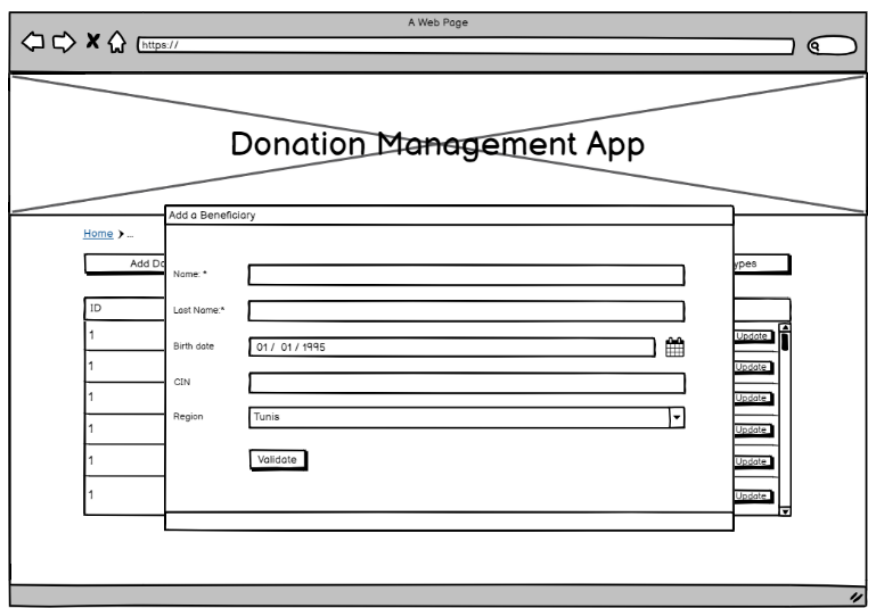

Figure 6. Add a beneficiary page mockup

Through the add a beneficiary pop up mentioned in the Figure 6, users can add a new beneficiary into the application system through writing the beneficiary First name, Last Name, Birth date, CIN, Region and then clicking on the validate button.

The Table 5 outline all the different blocks that exist in the Add a beneficiary page represented in The Figure 6 by defining the main functionality of each block.

Table 5. Add a beneficiary page elements descriptions

\begin{tabular}{|c|c|}
\hline Element & Description \\
\hline First Name & $\begin{array}{l}\text { The user should write in this input the name } \\
\text { of the first of the new beneficiary. }\end{array}$ \\
\hline Last Name & $\begin{array}{l}\text { The user should write in this input the last of } \\
\text { the new beneficiary. }\end{array}$ \\
\hline $\begin{array}{l}\text { Birth date/date } \\
\text { of creation }\end{array}$ & $\begin{array}{l}\text { The user should write in this input the birth } \\
\text { date of the new beneficiary. }\end{array}$ \\
\hline CIN/Fiscal ID & $\begin{array}{l}\text { The user should write in this input the } \\
\text { national card number of the new beneficiary. }\end{array}$ \\
\hline Region & $\begin{array}{l}\text { The user should choose through the } \\
\text { dropdown combo box the region name of the } \\
\text { new beneficiary. }\end{array}$ \\
\hline
\end{tabular}

\subsection{Add type}

Through the add a type pop up represented in the Figure 7, users can configure new donation type by providing its name in the input field.

The Table 6 illustrate the main component blocks in the Add a type page represented in The Figure 7 by defining the functionality of the type name input and how the user should interact with it.

\subsection{Statistics dashboard}


Through the statistics dashboard visualized in Figure 8, the user will have a clear vision regarding the latest statistics of the donations. The user will be able as well to predict which hospital (in case of using the application in the medical field) will have a shortage of medical supplies also he will be able to generate a PDF report directly from the application containing the latest statistics.

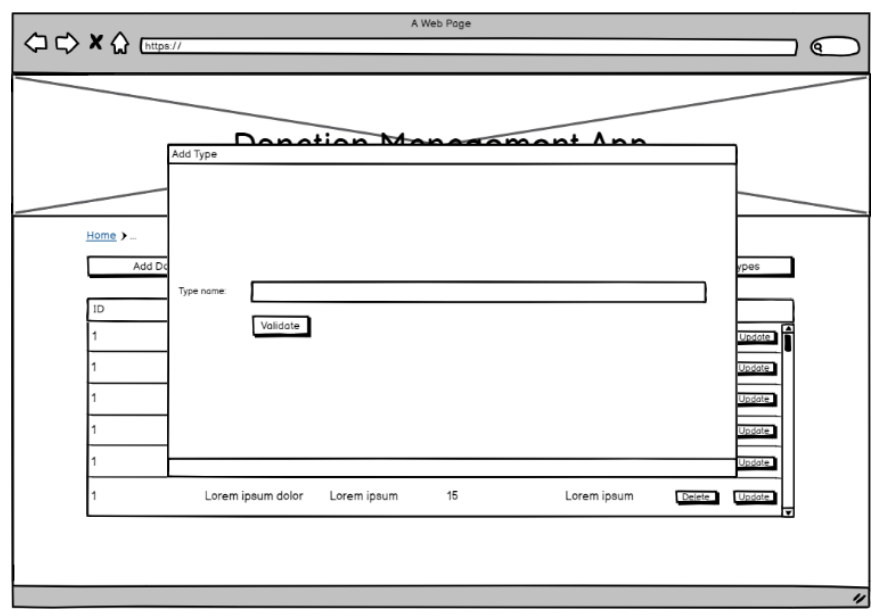

Figure 7. Add type page mockup

Table 6. Add type page elements descriptions

\begin{tabular}{|c|c|}
\hline Element & Description \\
\hline Type & the user should write in this input the new type \\
Name & name \\
\hline
\end{tabular}

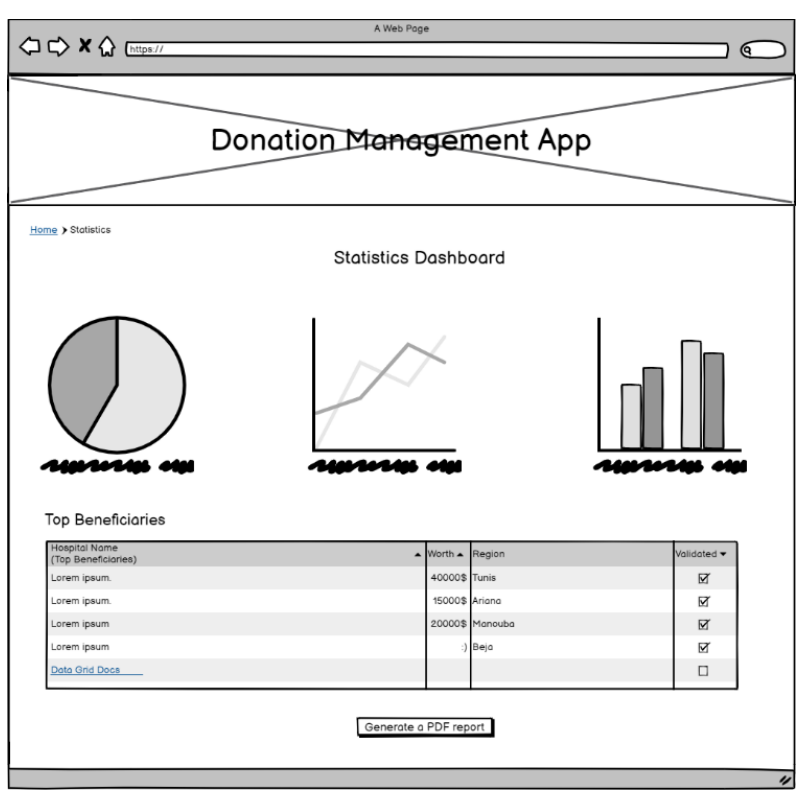

Figure 8. Statistics dashboard page mockup

Table 7. Statistics dashboard in page elements descriptions

\begin{tabular}{cc}
\hline Element & Description \\
\hline & Through clicking on the generate a report button a \\
& PDF document will be downloaded containing the \\
Generate & $\begin{array}{c}\text { latest statistics and the latest predictions regarding } \\
\text { the COVID-19outbreak in certain areas and its } \\
\text { possible effects which can challenge the medical } \\
\text { staff. }\end{array}$ \\
\hline
\end{tabular}

Through the displayed graphs on the dashboard the
user will have a clear visual representation of the
latest statistics.

The Table 7 describe all the different components and elements that exist in the statistics dashboard page represented in the Figure 8 by giving the main functionality of each component of the screen.

\section{CONCLUSION AND PERSPECTIVES}

The implementation of machine learning algorithm improves the business and research process to drive operational efficiency. It will revolutionarily affect the decision-making process. The implementation of $\mathrm{KNN}$ described in this paper is dynamic where each donation shared improves the accuracy of the classification and the deduction of the adequat beneficiaries.

This idea can help to fight COVID-19 but it still valid for other occasions like the problem of many countries due to the lack of medical supplies and hospitals that suffer from luck of funds.

In this article we have proposed our project which can manage donations transparently and include machine learning methods that make the process more intelligent. In future, we are thinking to improve our implementation, we realize that is important to improve data processing and may deploy other classification techniques to make from this project an application fully intelligent and independent.

Artificial Intelligence is very promising with several fields of application, a complex and divergent field build a motivation to seek and find solutions for current and future issues.

\section{REFERENCES}

[1] Lindmeier, C., Jasarevic, T. (2020). Who to accelerate research and innovation for new coronavirus. https://www.who.int/news/item/06-02-2020-who-toaccelerate-research-and-innovation-for-new-coronavirus.

[2] Murphy, K.P. (2012). Machine Learning: A Probabilistic Perspective. The MIT Press.

[3] Dasarathy, B.V. (1991). Nearest neighbor (NN) norms: NN pattern classification techniques. IEEE Computer Society Tutorial. https://ci.nii.ac.jp/naid/10012834200/en/.

[4] La Presse, Fonds 1818 près de $200 \mathrm{md}$ de dons, 07/05/2020. https://lapresse.tn/tag/fonds-1818/.

[5] Ministere de la Santé publique .http://www.santetunisie.rns.tn/ Street Djebel Lakhdhar, 1029 Tunis.

[6] Gofundme website. https://www.gofundme.com/.

[7] Yang, T., Cao, L.B., Zhang, C.Q. (2010). A Novel Prototype Reduction Method for the K-Nearest Neighbor Algorithm with $\mathrm{K} \geq 1$. In: Zaki M.J., Yu J.X., Ravindran B., Pudi V. (eds) Advances in Knowledge Discovery and Data Mining. PAKDD 2010. Lecture Notes in Computer Science, vol 6119. Springer, Berlin, Heidelberg. https://doi.org/10.1007/978-3-642-13672-6_10

[8] Dudani, S.A. (1967). The Distance-Weighted k-NearestNeighbor Rule. In IEEE Transactions on Systems, Man, and Cybernetics, SMC-6(4): 325-327. https://doi.org/10.1109/TSMC.1976.5408784 
[9] Cover, T., Hart, P. (1967). Nearest neighbor pattern classification. In IEEE Transactions on Information Theory, 13(1):

21-27. https://doi.org/10.1109/TIT.1967.1053964

[10] Denoeux, T. (1995). A k-nearest neighbor classification rule based on Dempster-Shafer theory. In IEEE Transactions on Systems, Man, and Cybernetics, 25(5): 804-813. https://doi.org/10.1109/21.376493

[11] Boateng, E.Y., Otoo, J., Abaye, D.A. (2020). Basic tenets of classification algorithms k-nearest-neighbor, support vector machine, random forest and neural network: A review. Journal of Data Analysis and Information Processing, 8(4): 341-357. https://doi.org/10.4236/jdaip.2020.84020

[12] Keller, J.M., Gray, M.R., Givens, J.A. (1985). A fuzzy K-nearest neighbor algorithm. In IEEE Transactions on Systems, Man, and Cybernetics, SMC-15(4): 580-585 https://doi.org/10.1109/TSMC.1985.6313426 